\title{
The GDC:
}

\section{A wolf in grandma's clothing}

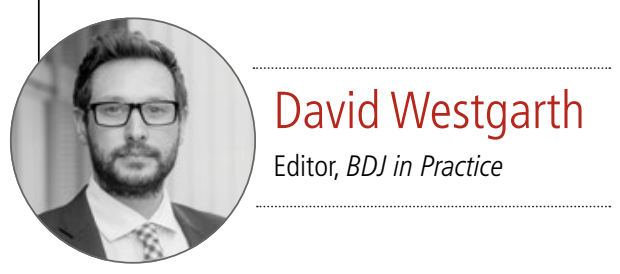

$\mathrm{L}$

ast month word broke of the General Dental Council spending a significant amount of money on undercover investigations, where in one such scenario the company which it hired posed as relatives of a sick pensioner.

The information, ascertained through a Freedom of Information Request by Dental Protection, found that between 2017 and 2018, the GDC paid $£ 17,064.85$ to private detective agency 'Invicta Investigation' to 'investigate complaints or information received in respect of a registrant's fitness to practise.'

It also revealed the GDC instructed an underguise operation where two private investigators attended an appointment with a dental technician posing as relatives of an elderly lady 'Evelyn' who needed new partial dentures but was very ill and could not attend in person.

Besides depicting a dental technician, who in this scene is played by Little Red Riding Hood, asking the GDC, played by the big bad wolf dressed as grandma, about what wonderful big teeth she did not have, the allegations pose more questions than answers.

And perhaps in a way the allegation is as disheartening as it is despicable. The GDC has made significant attempts to rectify the damaged relationship with its registrants. It's fair to say the level of distrust was at an all-time high five years ago, but ask any practitioner at the end of October whether that was still the case and you'd be hard-pressed to find the same level of antipathy as previously existed.

But now? Using registrants' money to pay for undercover investigators to follow up Fitness to Practise concerns? Trust is a fragile thing, and while the lowering of the Annual Retention Fee was a very welcome step in the right direction - an opinion not expressed only by myself, but by every dentist at the CDS Annual Conference in York the day the announcement was made - those at 37 Wimpole Street may come to regret the actions they have taken. Only time will tell whether that is the case, but I cannot imagine for one moment any dental practitioner wants to practise all the while thinking 'is this patient acting weird? It seems too perfect'. No practitioner wants to live in fear of entrapment by the very regulator they represent.

The other aspect is of course the balance between duty and ethical and moral behaviour. No-one disputes the GDC duty to investigate a registrant's fitness to practise if a patient or member of the public raises a concern. That is their remit. But is it morally and ethically acceptable to do so in such an apparently under-handed way?

Take the company's website, for example. At the top of the page of Invicta Investigation's testimonial page reads the following:

'The General Dental Council (GDC) have worked with Invicta Investigation for almost 3 years on cases that have involved investigation and evidence gathering where criminal offences have been alleged contrary to the Dentists Act 1984. These investigations mainly concern allegations of individuals practicing [sic] dentistry when not qualified and registered with the GDC.

Invicta Investigation have provided the GDC with an excellent service on all cases that have been sent to them, delivering results on time and within budget. They have always acted in accordance with instructions and within the law. On one occasion, in an emergency, Invicta Investigation were able to attend a venue within 3 hours of instructions being given.

The reports they provide are first-rate, comprehensive, clear and concise. I can thoroughly recommend them.' ${ }^{1}$

The testimony - undated - was supplied by 'Philip Blakebrough, Head of Fitness to Practise, Legal, General Dental Council'. Blakebrough has long since departed. Little wonder they needed to increase the ARF as a result of increased Fitness to Practise cases.

The idea that the regulator is employing morally and ethically questionable tactics to entrap morally and ethically questionable registrants is an irony hallmark that cannot be overlooked. Two wrongs do not make a right. A regulator should be upholding rules and regulations to their fullest, not engaging in the very same thing they're accusing registrants of.

These two points raised may be grounded in opinion, but the views of the Professional Conduct Committee in this case were not.

They found: 'there was no proper basis for reasonable suspicion of a commission of a regulatory breach which warranted the use of an under-guise investigation' and this resulted in an entirely inappropriate invasion of $[\mathrm{Mr}$ A's] professional workplace, where the scenario presented by the investigators to $[\mathrm{Mr} A]$ went beyond providing him with an unexceptional opportunity and amounted to inciting him to indicate that he may be prepared to act outside his scope of practice. ${ }^{2}$

When invited to comment, a spokesperson for the GDC said: 'There are a number of methods open to us in pursuit of this, including the use of external investigators, however this approach is one that is used in exceptional circumstances.

'The GDC has a legal duty to investigate fitness to practise concerns and where we are unable to rely on evidence from an informant for example where information which represents a potential danger to the public is sent to us anonymously - and where no alternate route is open, this is an option we may exercise.'

Make of that what you will. However one thing is certain; a wolf in grandma's clothes is not a practise any dental professional welcomes, and if the regulator wishes to continue to build upon its tentative bank of good will with registrants, it should think twice about whether this is a route it continues to exercise.

\section{References}

1. Invicta Investigations. Testimonial page. Available online at: http://www.invictainvestigation.co.uk/ testimonials.php (Accessed 11 November 2019).

2. BLM. The dark arts of the GDC: covert investigations and entrapment in healthcare regulation. Available online at: https://www.blmlaw.com/news/the-darkarts-of-the-general-dental-council (Accessed 11 November 2019).

https://doi.org/10.1038/s41404-019-0246-6 